Reseñ as

\title{
Ordóñez Morales, César Eduardo, 2006, Tendencias de la integración económica en Guatemala y el sureste de México, Universidad de San Carlos-Asociación para el Avance de las Ciencias Sociales en Guatemala, Guatemala.
}

E libro es una contribución que invita a pensar el pasado reciente y lo que está por venir en la frontera México-Guatemala. Es una propuesta para reflexionar en torno a las consecuencias de los procesos de integración comercial, en particular del Tratado de Libre Comerco (TLC) México-Guatemala. La preocupación del autor está centrada en los efectos de los procesos de integración en territorios fronterizos, en particular la frontera sur-occidental de Guatemala en la que, como señala el autor, una "dilatada ausencia de derechos económicos, sociales y culturales confluye con las más acentuadas dinámicas tendientes a la implementación de un modelo de modernización, colmado de complejas aristas e ilustrativas contradicciones".

El libro está dividido en dos secciones y varios anexos de información estadística que fundamentan la discusión de varios capítulos.

La primera sección, denominada conceptos y contextos, está integrada por cuatro capítulos, los dos primeros aluden a la parte conceptual sobre los temas de integración, globalización, regionalización, los países pequeños, las regiones fronterizas, el desarrollo y la integración. Los otros dos aterrizan en el proceso de integración económica Guatemala-México y en los aspectos geopolíticos de la región fronteriza.

En esta primera sección, el autor destaca el análisis en torno a los principales enfoques de la integración eco- nómica. Hace una revisión de los enfoques neoclásico, estructuralista y de la economía política. A este último dedica mayor atención pues es aquí donde discute la reestructuración capitalista, el proceso de globalización y regionalización, aspectos clave en la argumentación del libro. También explica los propósitos del Tratado de Libre Comercio de América del Norte (TLCAN) y del Área de Libre Comercio de las Américas (ALCA) y sus contenidos básicos. Sobre la marcha alude a la teoría de la dependencia, la integración y el desarrollo latinoamericanos, para luego hacer una reflexión crítica a la integración dependiente.

En lo que respecta a la reestructuración capitalista, analiza sus consecuencias en términos de la redefinición del espacio territorial, social y geopolítico. Sin embargo, hay un aspecto que requiere mayor discusión, que de hecho es un problema no resuelto; se trata de la relación bloques comerciales versus globalización. Para algunos especialistas la formación de bloques es parte de las expresiones de la globalización, incluso se podría ir más allá con el economista Paul Krugman, uno de los impulsores de la nueva geografía económica, cuando señala que la globalización se expresa de manera localizada. Inclusive refiere que no tiene sentido hablar de competencia entre países porque éstos no compiten entre sí como lo hacen las empresas. De manera que hay entre los estudios de la globalización tensiones que no terminan 
de aclararse, pero el libro muestra evidencias sobre las asimetrías de las regiones que generan problemas de integración regional en espacios de frontera.

Algo relevante que salta a partir de la lectura del libro de Ordóñez, que debe quedar como una tarea en la agenda de los estudiosos de los procesos de las nuevas integraciones, es revisar la idea de Gunnar Myrdal, retomada por Nicholas Kaldor y puesta al día por Paul Krugman: la tesis de la causación circular acumulativa. Esta idea expresa la concentración geográfica del capital humano, el crecimiento urbano, la concentración urbana, la estructura regional de la producción, las externalidades del sector industrial y la jerarquía de los sistemas de ciudades. Algunas explicaciones sobre las migraciones internacionales recientes están basadas en esta tesis; la región de estudio es particularmente rica en flujos migratorios por lo que resultaría interesante la exploración de la idea sugerida por Myrdal.

La segunda sección del libro se refiere a la integración fronteriza. El autor analiza la relación Guatemala-Sureste de México en la que propone una caracterización de las economías regionales. En un ámbito más concreto, refiere la integración económica en las regiones fronterizas y las relaciones surgidas del patrón de desarrollo regional.

El autor advierte que no existe todavía una teoría de la integración económica; sin embargo, plantea, en la primera parte del libro, las visiones sobre las cuales se han venido construyendo las integraciones en América Latina y que marcan, la diferencia entre las integraciones de los años sesenta y setenta, con respecto a las recientes integraciones cuyo propósito subyacente es la construcción de la hegemonía de los Estados Unidos.

Finalmente están los anexos, muy extensos, que proporcionan abundante información económica sobre México y Guatemala, los principales ejes de los negociaciones del TLC entre ambos países, estadísticas básicas sobre el sureste de México, las relaciones de integración, así como un modelo de simulación a partir de la inversión y la migración laboral en el área binacional suroccidental de Guatemala, Soconusco-Sierra Madre de Chiapas.
No es la intención comentar en destalle cada una de las partes que integran el libro. Sin embargo, el texto en su conjunto es relevante para la discusión de un aspecto central que le preocupa al autor: se trata de la distinción entre las fronteras externas e internas, cuya diferencia puede expresarse en grados de desarrollo, de ser marginal a tener un papel protagónico y beneficiarse del proceso de integración.

El autor señala con claridad las funciones y las ventajas de localización dependiendo de la naturaleza de las fronteras:

1. Si se trata de fronterasinternas, señala el autor, significa que hay mayores grados de apertura del mercado. En especial refiere la experiencia de Europa.

2. Pero si son fronteras externas, éstas tienden, sobre todo si se trata de economías fuertes o hegemónicas, a transferir, hacia las fronteras externas, funciones de su propia frontera, ya sea en lo económico o en lo geopolítico [control de flujos migratorios, seguridad, barreras comerciales, etcétera]. Es decir, son factores que generan exclusión para las sociedades vecinas fronterizas.

Las experiencias de integración fronteriza contribuyen a demostrar la importancia de dicha integración. El caso de la Unión Europea es paradigmático, en el que se puede observar grados de integración: macro, meso y micro, que tienen el propósito de favorecer las relaciones de vecindad y procesos de desarrollo local y regional. Ahí están, como señala el autor, las eurorregiones.

Por supuesto, la Unión Europea, a diferencia de otras regiones, tiene una larga experiencia en materia de integración: desde el Tratado de Roma, en los años cincuenta, pasando por la Comunidad Económica Europea en los ochenta y la Unión Europea en los noventa, con un proyecto político muy claro, no sin ausencia de tensiones.

La experiencia europea contrasta notablemente con la de la frontera México-Estados Unidos. En ésta, se trata de un proyecto político distinto donde se impone 
el poder del país más fuerte. Es una integración (más bien anexión) dependiente y subordinada. Es un caso paradójico en el que, de acuerdo con el autor, se trata de fronteras internas como parte del Acuerdo de Libre Comercio Trilateral (México-Estados Unidos-Canadá), pero que lejos de atenuar las asimetrías las profundiza.

El autor refiere otras experiencias, como la del MERCOSUR, en el que se podría decir que existe un proyecto político equiparable - guardando las debidas proporciones - con la Unión Europea. La pregunta, sin embargo, es si en países como los nuestros (México y Guatemala) es posible una integración donde los territorios fronterizos desempeñen un papel significativo en el desarrollo regional y nacional, y no sólo constituyan el traspatio para reducir costos como ocurre con la frontera México-Estados Unidos.

Al respecto, el autor señala que, el caso de la frontera México-Guatemala, se trata de una frontera que cumple funciones de seguridad del bloque económico del norte, sobre todo para la contención de migrantes con dirección a Estados Unidos. Es una región con una estructura económica primario-exportadora en condiciones de pobreza estructural y exclusión social.

En esta parte, el autor concluye diciendo: "el proceso actual de integración no presenta perspectivas favorables para reducir las desigualdades regionales de desarrollo para las regiones subnacionales, entre ellas las fronterizas, asunto que debería ser un aspecto relevante en la integración de los países latinoamericanos". Esta síntesis se expresa ampliamente en las consideraciones finales, de las que se pueden destacar los siguientes puntos:

1. El proceso de integración México-Guatemala forma parte de un proceso más amplio que se define bajo la hegemonía de Estados Unidos. Es una integración que sustituye la visión latinoamericanista del período de la industrialización por sustitución de importaciones.
2. La integración incrementó la brecha comercial a favor de México y la inversión de grupos empresariales mexicanos en Guatemala.

3. El TLC México-Guatemala es similar a la estructura del TLCAN: favorece la desregulación de la Inversión Extranjera Directa (IED) y el comercio, pero es desfavorable para las pequeñas economías, además de la ausencia en temas centrales como el social, en particular, el tema migratorio no está presente y que por su importancia reclama un lugar en la agenda de la integración, ambiental, desarrollo regional, cooperación fronteriza y derechos humanos.

4. Se da paso a otra integración formal con el Plan Puebla-Panamá (PPP) con una visión geopolítica de desarrollo capitalista, en torno a los recursos naturales estratégicos, infraestructura física, turismo, alivio a la pobreza, desarrollo humano, industria maquiladora articulada a la contención migratoria y aspectos de seguridad. Se puede añadir a lo que refiere el autor que el PPP representa un ingrediente adicional al proceso de integración continental, toda vez que no implica reformas en las disposiciones legales como en el caso de los TLC; es un proyecto fracasado en su aspiración para aliviar la pobreza y contener los flujos migratorios, pero, por otro lado, exitoso porque ha logrado avanzar en los proyectos carreteros y en la integración energética, necesarios para la dinámica de acumulación de capital en la región.

5. El TLC México-Centroamérica y el PPP son parte de un proceso económico y geopolítico que articula a esta región multinacional con el TLCAN y el ALCA. Esta conclusión lleva a la pregunta sobre lo que significa Centroamérica para México y para Estados Unidos, ahora que se ha ratificado el Tratado de Libre Comercio entre los países centroamericanos y Estados Unidos (CAFTA, por sus siglas en inglés). El autor considera que éste es un espacio 
de competencia y complementariedad para México y Estados Unidos; podríamos añadir que es mucho más que eso, que la parte económica es insignificante frente a la importancia del tema geopolítico, de contención de los "grandes amenazas" para Estados Unidos: migrantes, drogas y armas. Significa el control de un territorio estratégico para mantener bajo vigilancia lo que el gobierno de Washington ha dado en llamar su Tercer Frontera (el Caribe y la propia región centroamericana).

El libro de Ordóñez lleva a pensar en torno a las propuestas y procesos recientes. En particular en torno a las declaraciones del presidente Evo Morales sobre la comunidad sudamericana de naciones, un proyecto contestario a la integración analizada por el autor:
"Después de años de haber sido víctimas del mal llamado "desarrollo" hoy nuestros pueblos deben ser los actores de las soluciones a los graves problemas de salud, educación, empleo, distribución inequitativa de los recursos, discriminación, migración, ejercicio de la democracia, preservación del medio ambiente y respeto a la diversidad cultural". Estas palabras refuerzan la idea de la necesidad de pensar un nuevo tipo de integración en la que las fronteras recuperen centralidad en los procesos de desarrollo regional y local. También nos invita a profundizar en la discusión sobre los temas del desarrollo, las integraciones y el papel de las fronteras.

Daniel Villafuerte Solís CESMECA-UNICACH

Cuerpo académico: Política, diferencia y fronteras 